\title{
The two-component model of behavior factors: Evidences of orthogonality of explicit and implicit factors*
}

\author{
O.L. Chernozub \\ Institute for Social Action Research, \\ $2^{\text {nd }}$ Schemilovsky per., 2, Moscow, 127055, Russia \\ (e-mail:9166908616@mail.ru)
}

\begin{abstract}
There is a growing understanding in social sciences that even purposeful human behavior cannot be fully explained by rational motives. The 'behavioral economy' developed a program for studying economic behavior considering more factors than the blind pursuit of one's benefit. In social psychology, the theory of two groups of factors that influence human behavior has been developed: explicit factors are determined mainly by conceptual thinking, while implicit factors - by non-rational motives, often not obvious for the subject of action. It is argued that the study of both groups of factors is a prerequisite for the correct understanding and accurate prediction of behavior since they are of different nature, irreducible to each other, and have very different effects on behavior. The article focuses on the issue of the different nature of explicit and implicit factors. Can we say that the models of dual decision-making from social psychology are applicable to social action? We tested the nature of the interaction of the explicit and implicit components of the attitude towards the United Russia party with the basic judgments that, it would seem, should form this attitude. The results were paradoxical. It turned out that ideologically biased statements addressed to the political party form an attitude towards it on the implicit level. At the same time, the attitude to these statements depends on the attitude to the party, but at the rational level. Thus, this is a convincing evidence of the fundamentally different nature of explicit and implicit factors of social behavior.
\end{abstract}

Key words: factors of behavior; precursors of action; two-component model of behavioral factors; explicit factors; implicit factors; attitude; structural theory of attitude; dual process; anticipatory excitation of a situationally-dominant factor; GATO; TDA/TPB; IAT; MODE; RIM

\section{Insufficiency of explicit factors for explaining human behavior}

Until now, most theoretical models of human behavior are based on the postulate of the predominant rationality. For example, in economics, the entire neoclassical direction is built on the assumption that a person bases his actions on the results of collecting and critically evaluating as much information relevant to the decision as possible [13; 14]. Neo-institutionalism allows for 'limited rationality'; however, a critical examination of the initial data remains the basis for the decision and action. The inability to make a fully 'rational' decision within this paradigm arises not from the unwillingness or inability of individual, but from objective circumstances: lack of information, unjustifiably high costs of obtaining

* C O.L. Chernozub, 2022

The article was submitted on 07.09.2021. The article was accepted on 17.12.2021. 
complete information, etc. $[1 ; 2 ; 7 ; 16 ; 19 ; 20 ; 29 ; 35 ; 36 ; 37 ; 38 ; 39]$. The majority of economic theories proceed from the assumption that individuals strive to 'maximize utility', have rational preferences for event outcomes', act in their own interests; try to rely on the most complete information [40].

In sociology, the rationalistically-oriented theory of behavior in its most expanded form is represented by the Theory of Reasoned Action/Theory of Planned Behavior (TRA/TPB) [12]. This model of Fishbein and Ajzen consists in the successive retrospective tracking of the materialization of an action: the action is obvious and accessible to direct registration; is preceded by intention; intention is preceded by an attitude; attitude is based on ideas, convictions and beliefs of a person that have formed throughout life in the process of socialization. When a person needs to act, one activates the already existing attitude towards the object of action, which, being an a priori (prior to direct collision with it) formed typical program of action, offers a variant of action. Further, this initial course of action is critically examined by the individual on several levels. First, in the perspective of the so-called 'expectations of action': will such an action lead to the result that the individual expects and which will satisfy him? Moreover, the intended action is analyzed in the perspective of 'normative expectations': does the action correspond to the social norm? The final element of the analysis is connected with 'expectations of control': the individual checks the action that he is prepared to perform - is it realistic to complete and does he perform it of his own free will or is being forced? The end result of this analysis is acceptance or rejection of the course of action. It is argued that, all other things being equal, the likelihood of an action is higher if its subject is sure that he will receive the results he expects, that he acts in accordance with social norms of his own free will, and has reasonable chances for success. The classic version of 'escalation of action' according to the TDA/TPB model is presented at Figure 1.

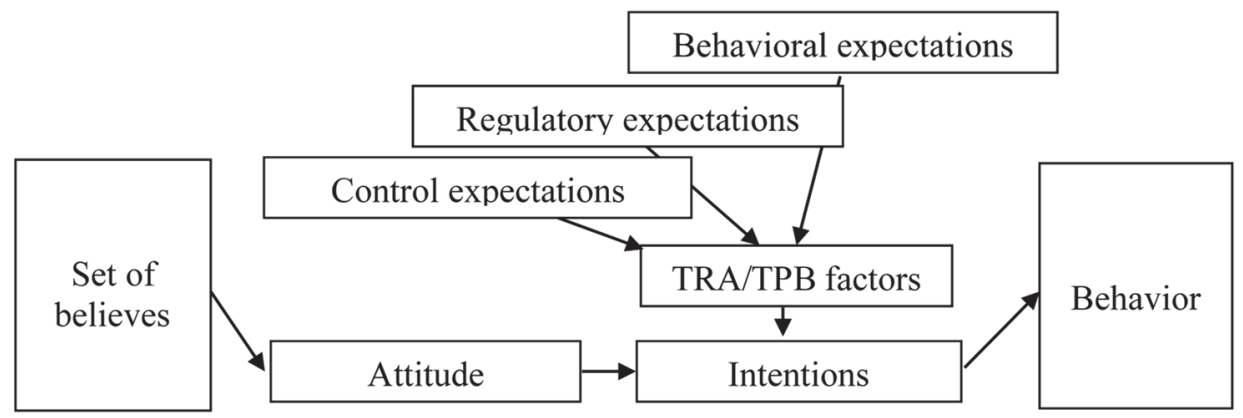

Fig 1. Classical (one-component) model of TRA/TPB behavioral factors

This approach has been criticized for the need to recognize a wider range of behavioral factors. In particular, models that are based on sensible, rational factors of behavior are considered not justified in theoretical terms and not able to convincingly explain the diverse human behavior $[16 ; 19 ; 29 ; 35]$. Thus, various theories have emerged, combining rational and non-rational factors of behavior 
$[8 ; 9 ; 15 ; 19 ; 33]$. Since, according to the practice of social measurements, the former are quite conscious phenomena relatively easily accessible for registration, they are usually associated with 'explicit' factors of behavior; while the second group of factors is relatively less accessible for direct fixation and may remain unrecognized not only by the researcher, but also by the respondent - the subject of the intended action; therefore, this group is associated with 'implicit' factors of behavior.

The presence of implicit factors of behavior is quite reliably established $[27 ; 28]$. Their influence on behavior is proven: if not direct, then at least through the mechanism of consistency/mismatch of the components of attitude $[5 ; 6 ; 17 ; 18$; $21 ; 24 ; 25 ; 26 ; 34]$. The nature of implicit factors remains not entirely clear. Presumably, they can significantly differ from explicit factors both in sources and in the nature of impact on human behavior [5]. In psychology, social psychology, cognitive science and neuroeconomics, the issues of the functioning of two different decision-making mechanisms have been developed in sufficient detail. In its most general form, the first is governed by the rules of conceptual thinking, and a person is fully aware of both the process and the rules of logical operations; the second mechanism is based on associative thinking, when the assessment of objects perceived by an individual is based on the principles of similarity-difference. The very process of forming chains of associative links is hidden from a person, in whose consciousness only the final result is reflected $[30 ; 31]$. To what extent can such a model, known as the dual-process theory of information processing, be integrated into the theory of social action in sociology? This question is posed [33], but has not yet received an unequivocal solution.

The purpose of this research is to test the explicit and implicit groups of behavioral factors for differences in their formation both by themselves (under the influence of more general 'initial' factors) and under the influence of the disturbing factor - in order to obtain empirical evidence of the fundamental applicability of the dual-process information processing models for explaining the mechanisms of the formation of behavior. We believe that this will allow to solve the following tasks: confirm the validity of identifying implicit factors of behavior as an independent group different from explicit factors; expand our understanding of the stability of differences in the behavior of explicit and implicit factors in the process of escalation of action; allow to understand reasons for these differences, linking them with the theories of dual-process information handling as well developed in scientific disciplines. The theoretical contribution of the work, therefore, consists of testing the validity for the sociological science of the main conclusions of theories of information processing, and in obtaining additional arguments in favor of one of the opposite interpretations of the interaction of explicit and implicit factors — 'sequential' [8; 9] or 'parallel' [19; 33].

\section{Theoretical model and central hypothesis of the research}

As a basic theoretical model of the study we used a two-component model of behavioral factors (based on the assumed interaction of explicit and implicit factors) $[3 ; 4 ; 5 ; 6 ; 10 ; 11 ; 27 ; 28]$. It is a classic model of the theory of reasoned 
action/planned behavior (TRA/TPB) enriched with an independent flow of implicit factors that ultimately influence behavior (Fig. 2).

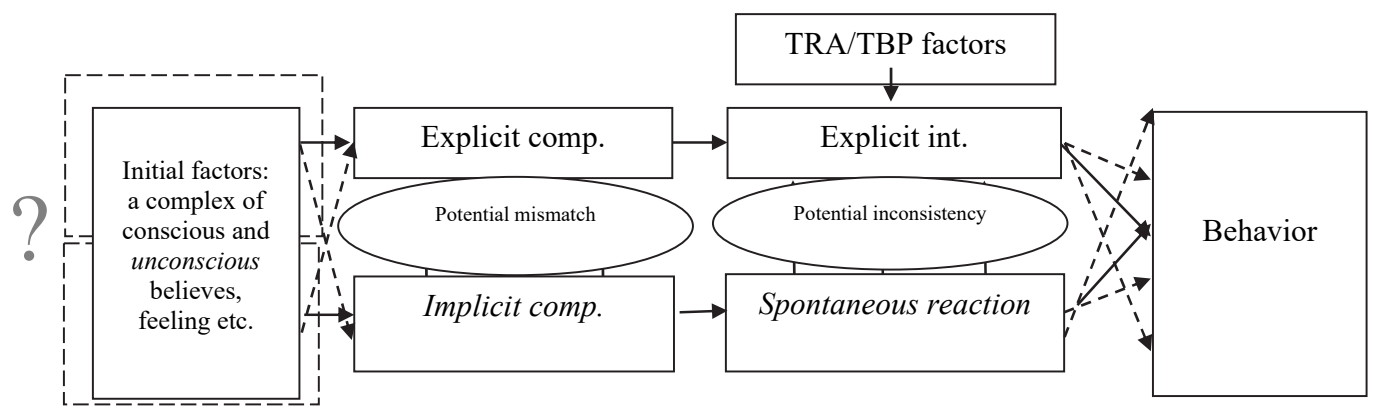

Fig 2. Two-component behavior prediction model

This model and the original TRA/TPB model are traditionally considered as having a single array of initial factors that influence the actual factors of behavior both explicit and implicit (the leftmost rectangle in Fig. 2). In fact, this is not obvious. If in the TRA/TPB the unity of initial factors was implied due to the unity of explicit influences, then within the two-component model this issue has not been studied. At the same time, the recognition of implicit factors of behavior as an independent stream of influences that ultimately affects the real action raises the question of their origin and dependence on deeper, 'initial' factors. In theoretical terms, the question is: is the block of initial factors a single one, or does it split into two (or more) independent areas differing in the nature of influence on explicit and implicit factors?

Methodologically, the answer to this question leads to the conclusion whether the block of initial factors is available for study by a universal set of research tools, or, due to their ontology, its various areas require independent, irreducible approaches. In the instrumental aspect, the study of these issues inevitably focuses on whether the validity, sensitivity and selectivity of the available measurement tools are satisfactory to confidently identify such differences.

Thus, the subject of the study was the discrepancy between explicit and implicit factors of behavior as expressed in differences in their reactions to the influence of initial factors. If explicit and implicit factors react to the influence of the same initial factors differently, then their nature, patterns of functioning and development should be significantly different and most probably irreducible to each other. The reaction of explicit and implicit factors to initial factors was to be investigated both in static and dynamic perspectives. In the static perspective, the coincidence or non-coincidence of such a reaction will be diagnosed by the trength and direction of the associations between the initial factor and the corresponding factor. In the dynamic perspective, the reaction of factors will be investigated through changes in these associations under the perturbations set by experimental influences from extraneous factors that are not included either in initial factors or in behavioral factors. The central hypothesis of the study was: 
"there are no differences in the response of explicit and implicit factors of behavior to the same initial factors". Empirically $\left(\mathrm{H}_{0} 1\right)$ : "there are no differences between explicit and implicit factors in terms of the strength and direction of associations with the target initial factors". Rejection of the hypotheses $\mathrm{H}_{0} 1$ will mean that there are grounds for recognizing the discrepancy between the nature of explicit and implicit factors of behavior.

\section{Operationalization of the model}

As an indicator of the state of the factors, the corresponding (explicit and implicit) components of the attitude in relation to the object of the intended action were chosen. The initial factors were statements about the presence of certain properties in the object, according to previous studies, essential for the formation of attitude. The criticality of the respondent in relation to various objects of the social-political sphere was identified as a disturbing factor. Criticality was chosen as an instrument of experimental influence due to the supposed pronounced asymmetry of influence. As a property of rational thinking, it should have a significant impact on the explicit behavioral factors and not the implicit ones. Even if such an influence manifests itself in relation to both groups of factors, it is logical to expect that there will be differences in the nature of this influence. Accordingly, the presence of such differences will indicate the unequal nature of explicit and implicit factors, with the theoretical consequence confirming the need to supplement any model of behavior factors with a group of implicit ones. The nature of these differences, if found, will make it possible to assess the possibility of explaining them from the standpoint of the theory of dual-process information processing.

The empirical basis of the study was the data of the WCIOM electoral panel held on the eve of the elections to the Russian State Duma in 2016 ( $\mathrm{N}=5248)$. The sample standard error is $2.25 \%$. The poll was conducted as part of the $4^{\text {th }}$ wave in August - September 2016 by the personal interview method, completed 7 days before the election day $[4 ; 5 ; 6]$. Provided the practical limitations of the available empirical material, our theoretical model turned out to be represented by the following set of measurable indicators: the explicit component of the attitude was represented with a variable formed by answers to the question of the correspondence of the victory of the United Russia party to the interests of the respondent (yes - no); the implicit component of the attitude was detected using the GATA (Graphical Associative Test of Attitude) - as the result of measuring the valence of an unconscious attitude towards the party (the original scale of eight divisions was reduced to two - positive - negative implicit attitude); the set of initial factors forming the component of the attitude was represented by a series of "ideologically biased statements about the United Russia (Table 1) and the question "Do you agree or disagree with the statement..." (the original scale was reduced from four to two ranks — strongly agree, rather agree, rather disagree, completely disagree). 
Ideologically biased statements

\begin{tabular}{|c|c|}
\hline Short title & Questionnaire \\
\hline Social justice & This is a party that advocates for the strengthening of social justice \\
\hline Reform party & $\begin{array}{c}\text { This is a reform party focused on change, new ideas and } \\
\text { approaches }\end{array}$ \\
\hline Party of common people & Most of the party members are ordinary people like me \\
\hline Party of real deeds & This is a party of real deeds. They fulfill their promises \\
\hline Will ensure the development & This is the party that can ensure the development of the country \\
\hline Interests of ordinary people & This party protects the interests of ordinary people \\
\hline Party of high morality & Most of the party members are people of high moral principles \\
\hline
\end{tabular}

The criticality status of the attitude was set by three variables, which formed three pairs of experimental and control groups: 1) the results of answering a direct question about the level of education - the experimental group was formed by respondents with several higher educations or an academic degree $(\mathrm{N}=302)$, the control group - with secondary and incomplete secondary education $(\mathrm{N}=1085)$; 2) the results of answering the question about the procedure for electing the State Duma deputies - the experimental group included those who answered the question correctly $(\mathrm{N}=1328)$, the control group - all the rest $(\mathrm{N}=3922) ; 3)$ the results of answering the question on confidence in political parties - the experimental group included respondents who answered that they 'rather trust' $(\mathrm{N}=1040)$, the control group - those who 'rather do not trust' political parties $(\mathrm{N}=2456)$. Thus, the set of initial variables was as follows:

- AExp - valency of the explicit component of the attitude

- AImp - valency of the implicit component of the attitude

- IF1-7 — status of consent with ideologically biased statement (7 variables)

- CE - education criticality status

- CA - criticality status on the basis of awareness of the procedure for electing deputies

- CT - criticality status based on a priori trust in political parties

Ultimately, seven measurement models were formed for the static comparative analysis (by the number of ideologically biased statements) (Fig. 3). For the dynamic comparative analysis, each of these models was perturbed by three variables reflecting different manifestations of criticality. Thus, the identification of the strength and nature of the associations between the degree of agreement with the ideologically biased statement and the valence of both components of the attitude was carried out separately for the group of relatively high criticality (experimental) and the group of relatively low criticality (control group) (Fig. 4). For clarity, gray dashed arrows are drawn on Figures 3 and 4 to indicate the objects of comparison within each of the applied types of analysis. 


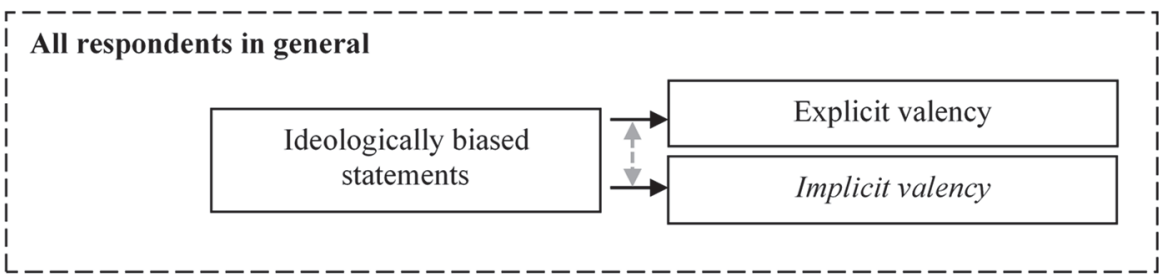

Fig. 3. Measurement model: static approach

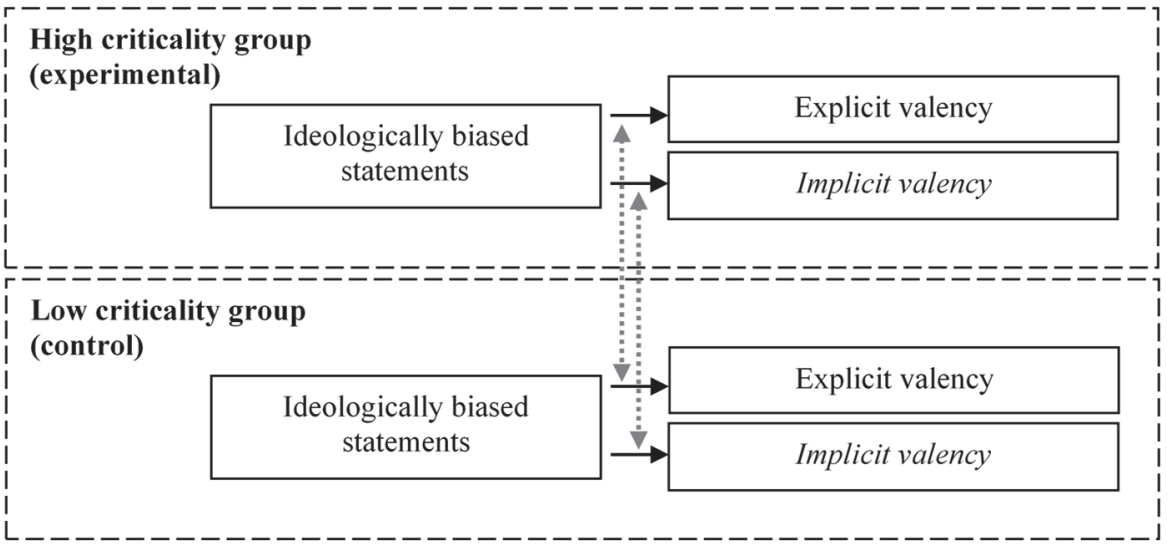

Fig. 4. Measurement model: dynamic approach

\section{The static perspective}

The main goal of the static comparative analysis was to test the hypothesis $\mathrm{H}_{0} 1$ : "there are no differences between explicit and implicit factors of behavior in terms of the strength and direction of associations between these factors and initial factors". For each pair of variables AExp vs IF1-7 and AImp vs IF1-7, the values of one-way associations as per Somers Delta were calculated. This statistical indicator was chosen based on its properties to most accurately reflect the directional dependence of variables with ordinal scales in general, and dichotomous scales in particular $[22 ; 23 ; 32]$. Since checking the directionality of the associations was one of the objectives, we did not have the opportunity to classify the variables a priori as dependent or independent. This circumstance, among other things, put forward the task of ensuring the maximum possible comparability of the scales. Based on this requirement, all variables were recoded into binomials.

The results of the calculations for all respondents are presented in Tables 2 and 3. In Table 2, the two left-hand columns with data reflect the degree of connection of agreement with the corresponding statement and the valence of the implicit component of the attitude in relation to the United Russia'. The two right columns with data - the degree of connection of the corresponding statement with the valence of the explicit component. Columns $\mathrm{D}$ show the value of the indicator, columns Sign - the statistical significance of the corresponding value. The data indicate that there is a noteworthy, statistically significant relationship between all the pairs of variables. For some statements, it is expressed relatively strongly (Party of real deeds, Will ensure the development of the country), for 
some, it is relatively weak (Party of reforms, Social justice), but in each case there is a relationship. Thus, there are virtually no differences between the strength of the interrelation of the initial factors and each of the component of the attitude. If our analysis stopped at this level, we would have to conclude that there is no reason to reject hypothesis $\mathrm{H}_{0} 1$.

Table 2

Ideologically biased statements and components of the attitude: symmetrical dependence (Somers' D, statistical significance)

\begin{tabular}{|c|c|c|c|c|}
\hline \multirow{2}{*}{ Component of the attitude } & \multicolumn{4}{|c|}{ All respondents } \\
\cline { 2 - 5 } & \multicolumn{2}{|c|}{ Implicit } & \multicolumn{2}{c|}{ Explicit } \\
& D & \multicolumn{1}{|c|}{ Sign } & D & 0 \\
\hline Social justice & 0.103 & 0 & 0.153 & 0 \\
\hline Reform party & 0.064 & 0.001 & 0.096 & 0 \\
\hline Party of common people & 0.107 & 0 & 0.169 & 0 \\
\hline Party of real deeds & 0.273 & 0 & 0.262 & 0 \\
\hline Will ensure the development & 0.28 & 0 & 0.255 & 0 \\
\hline Interests of ordinary people & 0.216 & 0 & 0.244 & 0 \\
\hline Party of high morality & 0.211 & 0 & 0.204 & 0 \\
\hline
\end{tabular}

The more detailed data characterizing not only the strength, but also the directionality of the association of each pair of variables are presented in Table 3 . In the columns Comp. the dependent variable is the corresponding component of the attitude, in the Stat. columns - the corresponding statement. Almost all the indicators passed the test of statistical significance with a confidence level of at least 0.05 . The only value for which this index is greater than 0.05 but remains less than 0.1 is shown in italics. For clarity purposes, the most significant differences $(>0.05)$ in the direction of the connection are highlighted in bold. As was already seen in Table 1, all the statements demonstrated a high degree of connection with at least one of the components of the attitude in relation to the object of these statements. Thus, we can reasonably conclude that the relationship between the attitude towards the United Russia and the degree of agreement with the presence of certain characteristics in it is pronounced and quite stable. And the nature of the influence of agreement with our statements on the implicit and explicit components of the attitude is not the same.

The fact of the prevailing influence of an explicit attitude towards the United Russia on agreement with the ideologically biased statements is quite unexpected. The average respondent does not treat the United Russia badly because he considers it, for example, incapable of ensuring the country's development, but on the contrary, he denies such an ability because he initially treats this party badly. The converse statement is also true: the survey participants have a positive attitude towards this party not because they consider it to be the owner of the considered 
positive qualities. On the contrary, they a priori ascribe these qualities to it, driven by their good attitude towards it at an explicit level.

Direction of the mutual influence of variables regardless of the level of criticality (Somers' D)

\begin{tabular}{|c|c|c|c|c|}
\hline \multirow{3}{*}{$\begin{array}{c}\text { Component of the attitude } \\
\text { Dependent variable }\end{array}$} & \multicolumn{4}{|c|}{ All respondents } \\
\hline & \multicolumn{2}{|c|}{ Implicit } & \multicolumn{2}{|c|}{ Explicit } \\
\hline & Comp. & Stat. & Comp. & Stat. \\
\hline Social justice & 0.115 & 0.093 & 0.119 & 0.213 \\
\hline Reform party & 0.072 & 0.057 & 0.075 & 0.136 \\
\hline Party of common people & 0.183 & 0.076 & 0.166 & 0.172 \\
\hline Party of real deeds & 0.306 & 0.246 & 0.2 & 0.377 \\
\hline Will ensure the development & 0.325 & 0.245 & 0.2 & 0.351 \\
\hline Interests of ordinary people & 0.251 & 0.189 & 0.188 & 0.348 \\
\hline Party of high morality & 0.236 & 0.19 & 0.158 & 0.29 \\
\hline
\end{tabular}

Methodologically, the deduction is obvious. If we limited ourselves only to the explicit component of the attitude, then an erroneous conclusion could be made about the incorrectness of considering the ideologically selected biased statements as the initial factors in the formation of the attitude. Indeed, despite the rather high strength of the relationship between the corresponding variables (Table 2), the direction of this relationship turns out to be inversely intuitive expected (Table 3). However, if we assume the presence of an implicit component, acceptance of such a conclusion becomes impossible. The data in Table 2 convincingly indicate that agreement with the statements has a pronounced influence on the attitude towards the party, although this influence is realized only at the implicit level. This gives grounds to assert that in relation to the implicit component of the attitude, the TRA/TPB model in terms of the influence of the complex of initial ideas and beliefs on the attitude finds its confirmation.

In the generalized form, our results are presented in Figure 5. The dots reflect the position of ideologically biased statements in space, one dimension of which is formed by the strength of the connection of the statement with the explicit, and the other - with the implicit component. The three distributions represent a symmetric association - 'the statement affects the component' and a directional association - 'the component affects the statement'.

The data in Figure 5 reflect the pattern, which reveals the general picture based on the results in Table 2: statements to a greater extent affect the implicit component, but they themselves depend more on the explicit one, which allows to formulate a hypothesis, quite possibly opening a new direction for further research. The trend function that most fully reflects the distribution logic according to the $\mathrm{R}^{2}$ criterion turned out to be the logistic function. It is not known how steadily this 
pattern will be reproduced in subsequent measurements, but it looks pronounced. In any case, the quality of the regression according to the available observations is high, and if we exclude from the distribution the only outlier associated with the statement 'Party of high morality' (the corresponding values are circled), the $\mathrm{R}^{2}$ indicator will closely approach 1 (Table 4).

\section{Influence of initial factors on the studied variables}

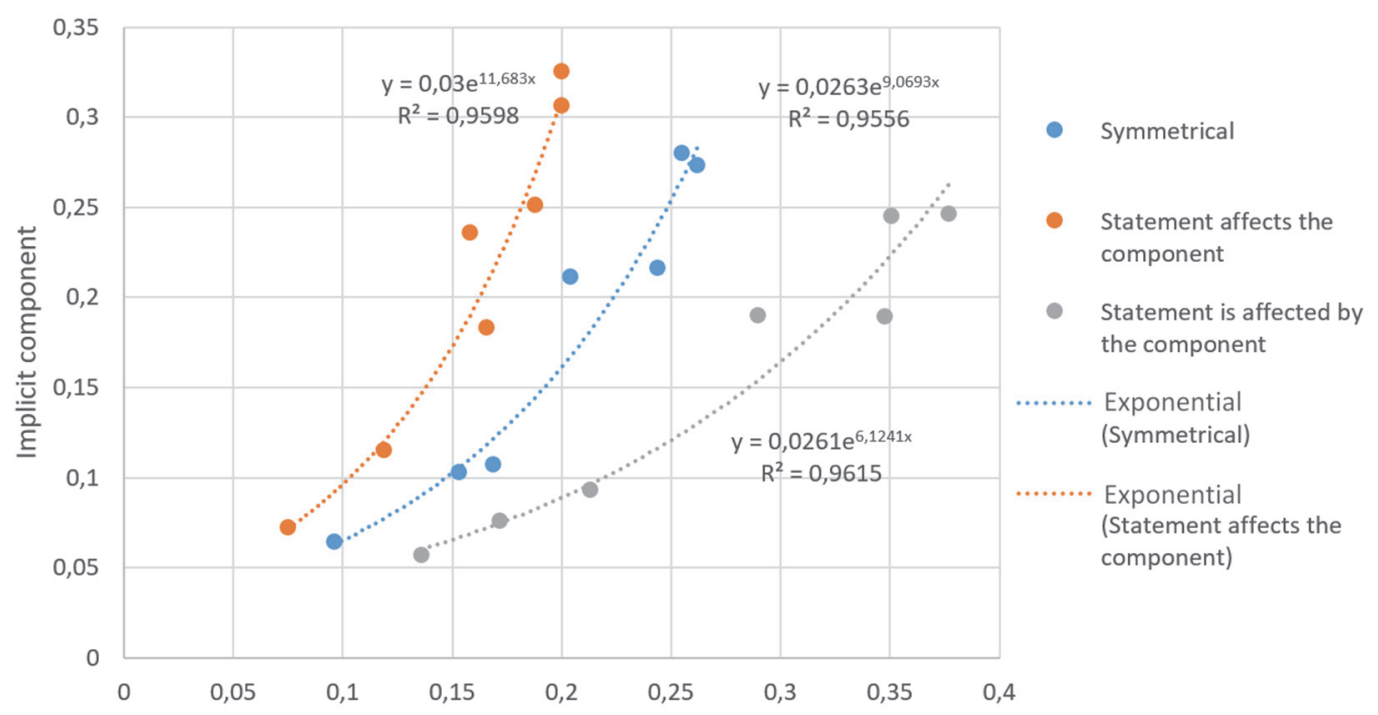

Fig. 5. Associations of the ideologically biased statements and the components of attitude

Table 4

Comparative quality of regression for different types of trend functions (indicator $\mathbf{R}^{2}$ )

\begin{tabular}{|c|c|c|c|}
\hline Function type & $\begin{array}{c}\text { Statement affects } \\
\text { the component }\end{array}$ & Symmetrical & $\begin{array}{c}\text { Statement is affected } \\
\text { by the component }\end{array}$ \\
\hline Linear & 0.907 & 0.92 & 0.944 \\
\hline Power & 0.945 & 0.935 & 0.969 \\
\hline Exponential & 0.96 & 0.956 & 0.962 \\
\hline Exponential without outlier & 0.989 & 0.987 & 0.984 \\
\hline
\end{tabular}

If we were not mistaken in typologizing the trend function, this means that the increase in the strength of the association between the variables under consideration is mainly provided by the growth of the functionality of the implicit component of our two-component model of behavior. At least for this particular case, the data indicate: the higher the interdependence between ideological biased statements and attitude, the more strongly this interdependence is determined by the influence of the statement on the implicit component of the attitude, and the weaker it depends on the explicit one. The stronger the connection, the more fully it is determined by implicit factors. 


\section{Expected findings and unexpected questions}

Thus, it has been reliably established that the nature of the connection between the initial factors, represented by ideologically biased statements, and the factors of behavior, represented by the explicit and implicit components of the attitude, is fundamentally different. Agreement with statements is a factor in relation to the implicit component, while the explicit component turns out to be a factor of agreement with statements. Although there is some variation in the strength of the associations in the data obtained, in none of the cases considered does this cast doubt on the 'counter' nature of the direction of such an influence. This allows to conclude that the explicit and implicit behavioral factors demonstrated a different nature of interaction with a set of initial factors. This means that the hypothesis $\mathrm{H}_{0} 1$ should be rejected.

The paradoxical situation associated with the counter-intuitive 'counter' direction of the influences between the analyzed variables cannot but draw attention. It would be understandable and easily explainable if such an influence rushed from the original factor to both the explicit and implicit factors - this would fit into the TRA/TPB. Likewise, it would be easy to explain an opposite situation, when the direction of influence goes from the factors of behavior to the assumed initial factor. In this case, we would have no reason to consider it as an 'initial' factor, and the question of the applicability of the TRA/TPB would not arise. The interaction identified would not be an interaction between initial factors and factors of behavior. The phenomenon of the opposite direction of influences was empirically registered.

In the most preliminary sense, it can be assumed that the revealed pattern arises as a result of the complex interaction between the components of the attitude. For example, the manifestation of certain properties of the object of attitude at the implicit level affects the attitude towards it, and this attitude, being conscious, is projected onto the explicit recognition of the presence of these properties in the object. Although at the moment we do not have a detailed argument, it looks quite acceptable and fits into the logic of both the MODE and RIM.

The phenomenon we discovered means the predominant use of non-rational, pre-conceptual channels for receiving and processing information in the subject area, where, it would seem (if we remain in the position of the predominant rationality of social behavior), the situation should be exactly the opposite. Perhaps, in the future, we would call this phenomenon 'cognitive reductions': in an environment requiring a rational decision, a person, for some reason, reduces his involvement and relies more on 'intuition' than on 'reasoning'. If this is indeed the case, then an additional opportunity is revealed to substantiate the applicability of the theories of dual-process information handling to the analysis of the factors of social action.

\section{References}

1. Allais M. Le comportement de l'homme rationnel devant le risque: critique des postulats et axiomes de l'ecole americaine. Econometrica. 1953; 21 (4).

2. Allais M., Hagen O. (Eds.) Expected Utility Hypothesis and the Allais Paradox. Dordrecht; 1979. 
3. Chernozub O.L. Revealing the affective component of the electoral attitude: Creating and validating a graphic associative attitude test. Monitoring of Public Opinion: Economic and Social Changes. 2018; 3. (In Russ.).

4. Chernozub O.L. Electoral forecasting based on data on intentions: Limits of accuracy of the conventional model and prospects for its development based on emotional factors. Monitoring of Public Opinion: Economic and Social Changes. 2018; 4. (In Russ.).

5. Chernozub O.L. Implicit factors and inconsistency of electoral behavior: From a theoretical concept to an empirical phenomenon. Monitoring of Public Opinion: Economic and Social Changes. 2020; 4.

6. Chernozub O.L. Implicit factors and inconsistency of electoral behavior: From attitude to behavior. Monitoring of Public Opinion: Economic and Social Changes. 2020; 5.

7. Ellsberg D. Risk, ambiguity, and the savage axioms. Quarterly Journal of Economics. 1961; 75 (4).

8. Fazio R. The role of attitudes in memory-based decision making. Journal of Personality and Social Psychology. 1990; 59 (4).

9. Fazio R. Attitudes as object-evaluation associations of varying strength. Social Cognition. 2007; 25 (5).

10. Festinger L. A Theory of Cognitive Dissonance. Evanston; 1957.

11. Festinger L., Carlsmith J. M. Cognitive consequences of forced compliance. Journal of Abnormal and Social Psychology. 1959; 58 (2).

12. Fishbein M., Ajzen I. Predicting and Changing Behavior: The Reasoned Action Approach. New York; 2011.

13. Friedman M., Savage L.J. Utility analysis of choices involving risk. Journal of Political Economy. 1948; 56.

14. Friedman M. Price Theory. Chicago; 1976.

15. Gilovich T., Griffin D. Introduction - heuristics and biases: Then and now. T. Gilovich, D. Griffin, D. Kahneman. (Eds.). Heuristic and Biases: The Psychology of Intuitive Judgment. New York; 2002.

16. Goldstein D.G., Gigerenzer G. Models of ecological rationality: The recognition heuristic. Psychological Review. 2002; 109 (1).

17. Greenwald A.G., Poehlman T.A., Uhlmann E. L., Banaji M.R. Understanding and using the Implicit Association Test: III. Meta-analysis of predictive validity. Journal of Personality and Social Psychology. 2009; 97 (1).

18. Greenwald A.G., Smith C.T., Sriram N., Bar-Anan Y., Nosek B.A. Implicit race attitudes predicted vote in the 2008 U.S. Presidential Election. Analyses of Social Issues and Public Policy. 2009; 9.

19. Kahneman D., Frederick S. Representativeness revisited: Attribute substitution in intuitive judgment. T. Gilovich, D. Griffin, D. Kahneman (Eds.). Heuristic and Biases: The Psychology of Intuitive Judgment. New York; 2002.

20. Kahneman D. Thinking, Fast and Slow. New York; 2011.

21. Metcalfe J., Mischel W. A hot/cool-system analysis of delay of gratification: Dynamics of willpower. Psychological Review. 1999; 106.

22. Newson R. Parameters behind 'nonparametric' statistics: Kendall's tau, Somers' D and median differences. Stata Journal. 2002; 2 (1).

23. O'Connell A.A. Logistic Regression Models for Ordinal Response Variables. Sage; 2006.

24. Perugini M. Predictive models of implicit and explicit attitudes. British Journal of Social Psychology. 2005; 44.

25. Perugini M., Richetin J., Zogmaister C. Prediction of behavior. Handbook of Implicit Social Cognition: Measurement, Theory, and Applications. Guilford Press; 2010.

26. Roccato M., Zogmaister C. Predicting the vote through implicit and explicit attitudes: A field research. Political Psychology. 2010; 31.

27. Rosenberg M.J. Cognitive structure and attitudinal affect. Journal of Abnormal and Social Psychology. 1956; 53 (3). 
28. Rosenberg M.J., Hovland C.I., McGuire W.J., Abelson R.P., Brehm J.W. Attitude Organization and Change: An Analysis of Consistency among Attitude Components. Oxford; 1960.

29. Shah A.K., Oppenheimer D.M. Heuristics made easy: An effort-reduction framework. Psychological Bulletin. 2008; 134 (2).

30. Sloman S.A. The empirical case for two systems of reasoning. Psychological Bulletin. 1996; $119(1)$.

31. Smith E.R., DeCoster J. Dual-process models in social and cognitive psychology: Conceptual integration and links to underlying memory systems. Personality and Social Psychology Review. 2000; 4 (2).

32. Somers R.H. A new asymmetric measure of association for ordinal variables. American Sociological Review. 1962; 27 (6).

33. Strack F., Deutsch R. Reflective and impulsive determinants of social behavior. Personality and Social Psychology Review. 2004; 8.

34. Strack F., Neumann R. Furrowing the brow may undermine perceived fame: The role of facial feedback in judgments of celebrity. Personality and Social Psychology Bulletin. 2000; 26.

35. Thaler R.H. Misbehaving: The Making of Behavioral Economics. New York; 2015.

36. Tintner G. The pure theory of production under technological risk and uncertainty. Econometrica. 1941; $9(3 / 4)$.

37. Tintner G. The theory of choice under subjective risk and uncertainty. Econometrica. 1941; $9(3 / 4)$.

38. Tintner G. A contribution to the nonstatic theory of production. Studies in Mathematical Economics and Econometrics. Chicago; 1942.

39. Tversky A., Kahneman D. Advances in prospect theory: Cumulative representation of uncertainty. Journal of Risk and Uncertainty. 1992; 5 (4).

40. Weintraub E.R. Neoclassical Economics. The Concise Encyclopedia of Economics. URL: http://www.econlib.org/library/Enc1/ NeoclassicalEconomics.html

DOI: 10.22363/2313-2272-2022-22-1-70-83

\title{
Двухкомпонентная модель факторов поведения: свидетельства ортогональности эксплицитных и имплицитных факторов*
}

\author{
О.Л. Чернозуб \\ Институт исследований социального действия \\ 2-ой Щемиловский пер, 2, Москва, 127055, Россия \\ (e-mail: 9166908616@mail.ru)
}

\begin{abstract}
Аннотация. В социальных науках растет понимание того, что даже целенаправленное поведение человека не может быть полностью объяснено рациональными мотивами. «Поведенческая экономика» провозгласила программу изучения экономического поведения, учитывающую больше факторов, чем слепое стремление к собственной выгоде. В социальной психологии активно развивается теория двух групп факторов, влияющих на поведение человека: явные факторы определяются в основном понятийным мышлением, в то время как неявные - нерациональными мотивами, часто неочевидными для самого субъекта действия.
\end{abstract}

\footnotetext{
* (С) Чернозуб О.Л., 2022

Статья поступила 07.09.2021 г. Статья принята к публикащии 17.12.2021 г.
} 
Утверждается, что изучение обеих групп факторов - необходимое условие правильного понимания и точного прогнозирования поведения, поскольку они имеют разную природу, не сводимы друг к другу и оказывают разное влияние на поведение. Статья посвящена проблеме различной природы явных и неявных факторов. Применимы ли социально-психологические модели двойственных процессов принятия решений к социальному действию? Мы проверили характер взаимодействия явной и неявной составляющих отношения к партии «Единая Россия» с основными суждениями, которые, казалось бы, должны формировать это отношение. Результаты оказались парадоксальными. Выявление неявных факторов поведения позволяет лучше понять социальное поведение человека, а проекция соответствующих моделей смежных наук значительно обогащает социологические выводы. Оказалось, что идеологически смещенные высказывания в адрес политической партии формируют установку к ней на имплицитном уровне. Причем отношение к этим высказываниям зависит от установки к партии, но уже на рациональном уровне. Это убедительное свидетельство принципиально различной природы эксплицитных и имплицитных факторов социального поведения.

Ключевые слова: факторы поведения; двухкомпонентная модель поведенческих факторов; эксплицитные факторы; имплицитные факторы; установка; структурная теория установки; упреждающее возбуждение ситуационно-доминирующего фактора; GATO; TRA/TPB; IAT; MODE; RIM 